\title{
Políticas de Educação Infantil: conquistas, embates e desafios na construção de uma Pedagogia da Infância
}

\author{
Early Childhood Education Policies: \\ achievements, conflicts and challenges in \\ the construction of an Early Childhood Pedagogy
}

\author{
Rodrigo Saballa de CARVALHO'
}

Bianca Salazar GUIZZO²

\begin{abstract}
Resumo
A partir do campo das Políticas de Educação Infantil, o artigo tem como objetivo problematizar os modos de legislar a Educação Infantil no Brasil. Metodologicamente, é traçado um panorama das políticas de Educação Infantil com base na análise de documentos produzidos após a Constituição Federal de 1988. São destacados as conquistas, os embates e os desafios que têm sido enfrentados no campo da Educação Infantil. Conclui-se que os modos de educar as crianças têm constituído uma arena de disputas produzida em um sistema de relaçóes de poder, no qual direitos sociais conquistados precisam ser reafirmados para que náo sejam perdidos.
\end{abstract}

Palavras-chave: Educação Infantil. Políticas Educacionais. Pedagogia da Infância.
Abstract

From the field of Early Childhood Education Policies, the article aims to problematize the modes of legislating Early Childhood Education in Brazil. Methodologically, an overview of the Early Childhood Education policies is delineated based on the analysis of documents produced after the Federal Constitution of 1988. The achievements, conflicts and challenges that have been experienced in the field of Early Childhood Education are highlighted. In conclusion, the modes of educating children have been an arena of disputes produced in a system of power relations, in which historically conquered social rights need to be reaffirmed so that they are not lost.

Keywords: Early Childhood Education. Education Policies. Early Childhood Pedagogy.

1 Pós-doutor em Educação pela Universidade Federal de Pelotas (UFPEL). Doutor em Educação pela Universidade Federal do Rio Grande do Sul (UFRGS). Professor e pesquisador do Programa de Pósgraduação em Educação da Universidade Federal do Rio Grande do Sul (PPGEDU/UFRGS). Professor da área de Educação Infantil da Faculdade de Educaçâo da UFRGS. Grupo de Pesquisa em Linguagens, Currículo e Cotidiano de bebês e crianças pequenas (UFRGS) e Grupo de Estudos em Educação Infantil (UFRGS). E-mail: <rsaballa@terra.com.br $>$. Avenida Paulo Gama, s/n, bairro Farroupilha, Porto Alegre/ RS. Tel.: (51) 33083985.

2 Pós-doutora em Ciências da Educação pela Universidade de Bolonha. Doutora em Educação pela Universidade Federal do Rio Grande do Sul (UFRGS). Professora e pesquisadora no Curso de Pedagogia e no Programa de Pós-Graduação em Educação na Universidade Luterana do Brasil (ULBRA). Grupo Cultura e Educação (ULBRA) e Grupo de Estudos de Educação e Relação de Gênero (UFRGS). Av. Farroupilha, 8001, prédio 14, sala 207, Canoas/RS. Tel.: (51)998049800. E-mail: <bguizzo_1@hotmail.com>.

R. Educ. Públ.

Cuiabá

v. 27

n. 66

p. $771-791$

set./dez. 2018 


\section{Introdução}

Marco Polo descreve uma ponte, pedra por pedra. - Mas qual é a pedra que sustenta a ponte? - pergunta Kublai Khan. - A ponte náo é sustentada por esta ou aquela pedra - responde Marco - mas pela curva do arco que estas formam. Kublai Khan permanece em silêncio, refletindo. Depois acrescenta: - Por que falar das pedras? Só o arco me interessa. Polo responde: - Sem pedras o arco não existe. (CALVINO, 1990, p. 79).

O diálogo entre Marco Polo e Kublai Khan, descrito na obra As cidades invisiveis, de Italo Calvino (1990), é potente como metáfora para pensarmos as lutas políticas e sociais (TELES, 2015) que foram e ainda estão sendo travadas em nosso país para assegurar um atendimento de qualidade na Educação Infantil às crianças de 0 a 5 anos deidade. Ainda nos encontramos longe de terminarmos a construção do arco que forma a ponte descrita por Marco Polo, mas o exercício de descrição das pedras - das conquistas e dos desafios a serem enfrentados nos torna conscientes de nossa responsabilidade ética, política e social como responsáveis pela educação das crianças.

Nesse contexto, o presente artigo é decorrente de uma pesquisa que, a partir do campo de estudos das Políticas de Educação Infantil (NUNES; CORSINO, 2009; CAMPOS, 2012; AMORIM; DIAS, 2012; CRAIDY; BARBOSA, 2012; LEITE FILHO; NUNES, 2013; CRAIDY, 2014; FLORES; ALBUQUERQUE, 2015; CAMPOS; BARBOSA, 2015; CARVALHO, 2015, 2016) e das contribuições dos Estudos da Infância (BUJES, 2002; PENN, 2002; BARBOSA, 2010; MOSS, 2011; FOCHI, 2015), tem como objetivo elucidar e problematizar os modos de legislar a Educação Infantil no Brasil.

Para tanto, metodologicamente, é traçado um panorama das Políticas de Educação Infantil com base na análise de documentos produzidos após a Constituição Federal de 1988 (BRASIL, 1988). São destacadas as conquistas em relação à educação das crianças, bem como os embates e os desafios que têm sido enfrentados no campo da Educação Infantil em nosso país. A importância de tal panorama justifica-se no fato de que, no âmbito das políticas educacionais (SHORE; WRIGHT, 1997), os modos de educar as crianças constituem um espaço estrategicamente fabricado em um sistema complexo de relaçóes de poder (CARVALHO, 2015). Esse sistema deve ser descrito e discutido para que direitos sociais adquiridos no que diz respeito à Educação Infantil não sejam de forma alguma deixados em segundo plano. 
Conforme salientam Campos e Barbosa (2015), a Educação Infantil como política pública educativa decorreu de um intenso e longo processo de lutas, no qual os movimentos sociais assumiram o protagonismo. Cabe destacar que essas lutas marcantes foram travadas por mães trabalhadoras, por militantes dos movimentos sociais e também pelos pesquisadores da infância (que compunham a comunidade epistêmica da área) para que as crianças, até então concebidas como objeto de tutela, passassem a ser reconhecidas como sujeitos de direitos na Constituição Federal de 1988 (NUNES; CORSINO, 2009).

Nesse sentido, houve um avanço na área da Educação Infantil, que passou a ser entendida como campo de conhecimento, de atuação profissional e de política pública educacional em decorrência do aparato legal posterior à Constituição, o qual reconheceu o direito da criança a um atendimento de qualidade em instituiçôes educacionais (BUJES, 2002; CRAIDY, 2014). A Educação Infantil deixou de ter como parâmetro as políticas de assistência, recreação e saúde para ser entendida como um assunto educacional. No âmbito da legislação, a criança começou a ser vista como foco do processo educativo, tendo direito à educação formal.

$\mathrm{Na}$ mesma direção, ocorreu o reconhecimento legal da área de Educação Infantil a partir da Constituição Federal de 1988 (BRASIL,1988), do Estatuto da Criança e do Adolescente (BRASIL, 1990), da Lei de Diretrizes e Bases da Educação Nacional (BRASIL,1996), do Referencial Curricular Nacional para a Educação Infantil (MEC, 1998), das Diretrizes Curriculares Nacionais para a Educação Infantil (BRASIL, 2010) e dos Planos Nacionais de Educação (BRASIL, 2001, 2014).

Por outro lado, de acordo com Campos (2012), embora as conquistas legais tenham possibilitado a construção de um novo olhar sobre a Educação Infantil, ainda são inúmeros os desafios a serem enfrentados no campo pedagógico e político na luta pela construção de uma Pedagogia da Infância. No campo pedagógico, conforme alertam Moss (2011) e Campos (2012), está sendo construída uma nova concepção sobre como educar e cuidar em instituiçóes educacionais, tendo em vista a problematização e a superação das duas formas históricas que caracterizaram o atendimento das crianças no país: a assistencialista e a escolarizante. A assistencialista desconsidera a especificidade educativa das crianças que frequentam a Educação Infantil, evidenciando-se um deslocamento do direito social para a defesa da filantropia e do voluntariado como modo de alívio da pobreza (CARVALHO, 2016). Já a forma escolarizante se fundamenta em uma lógica propedêutica de ensino orientada por práticas do Ensino Fundamental (MOSS, 2011) que visam ao desenvolvimento de capital humano desde a mais tenra idade. 
Em relação à forma escolarizante, Campos (2012) destaca três aspectos a serem problematizados: 1) o fato de a Educação Infantil estar subordinada ao Ensino Fundamental,com base em um processo de colonização; 2) a visão economicista de educação, pautada em uma lógica neoliberal fundamentada em parâmetros de produtividade, os quais entendem as crianças como capital humano no qual se deve investir desde a mais tenra idade como forma de alívio da pobreza e, consequentemente, diminuição da desigualdade social dos países de terceiro mundo; 3) o entendimento de que a Educação Infantil pode reduzir o fracasso escolar das crianças, desde que as prepare adequadamente para os níveis subsequentes de educação, elevando o nível do país em avaliaçóes de larga escala, as quais têm sido a marca das políticas avaliativas contemporâneas.

No que diz respeito ao campo político, é possível afirmar que os desafios se acentuaram ainda em 2006, quando as crianças de 6 anos de idade foram transferidas da Educação Infantil para o Ensino Fundamental pela Lei n. ${ }^{\circ}$ 11.114, de 16 de maio de 2005, a qual instituiu o início da obrigatoriedade do Ensino Fundamental aos 6 anos (CRAIDY; BARBOSA, 2012; LEITE; NUNES, 2013). Em 2009, a Educaçáo Infantil sofreu um novo assédio com a Emenda Constitucional n. ${ }^{\circ}$ 59, de 11 de novembro, a qual tornou obrigatória a matrícula de crianças de 4 anos na primeira etapa da Educação Básica.

A matrícula na Educação Infantil a partir dos 4 anos de idade foi instituída pela Lei n. ${ }^{\circ} 12.796$, de 4 de abril de 2013 , tornando confuso o entendimento entre o que é considerado direito das famílias e o que é sua obrigação (CRAIDY, 2014) em relação à matrícula das crianças. Isso porque a creche e a pré-escola já eram um direito conquistado na Constituição Federal de 1988. Com a definição da obrigatoriedade da pré-escola, essa passou de direito à obrigação das famílias, as quais não podem mais escolher se desejam ou náo matricular as crianças aos 4 anos na escola. Além disso, como historicamente tem ocorrido, o grande desafio do atendimento das crianças de 0 a 3 anos permaneceu em segundo plano, sem nenhuma medida efetiva (CRAIDY, 2014).

Com base na discussão inicial apresentada, convém esclarecer que o artigo está organizado em quatro seçóes. Na primeira seção, é apresentado o cenário das conquistas legais que garantiram à Educação Infantil se tornar um direito das crianças. Na segunda seção, é focalizada a emergência das políticas de currículo para a Educação Infantil e as tensôes, os embates e as proposiçôes que envolveram tal processo. Na terceira seção, são discutidos os impasses enfrentados pelo campo da Educação Infantil no Brasil a partir da ampliação do Ensino Fundamental para 9 anos (Lei n.o 11.114/2005), da realizaçáo de um estudo-piloto de aferiçáo do desenvolvimento infantil por meio da avaliação de larga escala ASQ-3 (Ages and Stages Questionaries) nas creches municipais de Educação Infantil do Rio 
de Janeiro, em 2010, da obrigatoriedade da pré-escola aos 4 anos (Lei n. ${ }^{\circ}$ 12.796/2013), bem como do recente decreto que instituiu o Programa Criança Feliz (Decreto n. ${ }^{0} 8.869$, de 5 de outubro de 2016). Por fim, na quarta seçáo, são delineados os atuais desafios quantitativos de expansão do atendimento da Educação Infantil para as crianças de 0 a 3 anos e os desafios qualitativos de discussão da Base Nacional Comum Curricular (BNCC- MEC, 2017), tendo em vista a operacionalização efetiva das orientaçóes expressas nas Diretrizes Curriculares Nacionais para a Educação Infantil (BRASIL, 2010).

\section{Cenário de conquistas: Educação Infantil como direito das crianças}

A Constituição Federal de 1988 é um marco legal importante, pelo fato de ter reconhecido a criança e o adolescente como sujeitos de direitos e definido o atendimento à criança pequena como responsabilidade do Estado para com a Educação (CRAIDY, 2014; FLORES; ALBUQUERQUE, 2015). Por conseguinte, a educação das crianças, entendida até então como assistência, "[...] passou a figurar como direito do cidadáo e dever do Estado, a partir de uma perspectiva educacional, em resposta aos movimentos sociais em defesa dos direitos das crianças." (LEITE; NUNES, 2013, p. 70). Dessa maneira, a Constituição, ao instituir creches e pré-escolas sob a nomenclatura de Educação Infantil, como direito de todas as crianças desde o nascimento, ratificou os argumentos de política pública universal.

Embora, em termos práticos, o que foi proposto na Constituição não tenha se consolidado efetivamente até os dias atuais, essa legislação pode ser considerada exemplar, pois garantiu a igualdade de direitos entre o homem e a mulher, reconhecendo o papel conquistado pela mulher na vida pública e no mundo do trabalho (TELES, 2015). Assim, além de ser direito da criança, a Educação Infantil tornou-se um direito das famílias. Ou seja, a uma nova visão de infância passou a corresponder uma nova concepção de família e de papel do Estado. Corroborando tal perspectiva, é possível afirmar que a Educação Infantil se tornou fruto da democracia, bem como condição de sua consolidação (LEITE; NUNES, 2013).

Em 1990, em consequência de debates articulados entre o Estado e entidades da sociedade civil organizada, foi homologado o Estatuto da Criança e do Adolescente (ECA - Lei n. ${ }^{0} 8.069$, de 13 de julho de 1990), o qual reafirmou o direito constituinte da criança pequena à educaçáo. $\mathrm{O}$ ECA ratificou o direito constitucional à educação, "[...] a ser garantido à criança e ao adolescente 
brasileiros, declarando também o dever do Estado em assegurar-lhes o direito mediante o atendimento em creches e pré-escolas para as crianças menores de seis anos de idade." (FILHO; NUNES, 2013, p. 73). Isso significa que o ECA reconheceu as crianças como pessoas em condiçóes específicas de desenvolvimento e contribuiu potentemente para a construção da visão de criança como cidadá.

Diante dessa lógica - da criança entendida como cidadá, teve início a elaboração e a publicaçáo de programas e documentos oficiais relativos à Educação Infantil no país. Dentre os programas produzidos pelo governo federal, é importante ressaltar, em 1990, o Projeto de Educação por Multimeios para a formação de professores de pré-escola. Conforme destaca Carvalho (2015), o projeto foi desenvolvido por meio de orientaçóes didáticas para o trabalho com música, dança, expressão artística, ciências, jogos, brincadeiras, linguagem escrita e aritmética a ser realizado com as crianças.

Nesse cenário, a primeira Política Nacional de Educação Infantil foi definida em 1994, focalizando a elaboração de propostas curriculares para as crianças em creches e pré-escolas e definindo que o currículo da Educação Infantil deveria ter como parâmetro o reconhecimento do nível de desenvolvimento das crianças, a diversidade social, cultural e os conhecimentos a serem abordados (FILHO; NUNES, 2013). Tendo em conta esses aspectos, Amorim e Dias (2012) argumentam que o objetivo da política proposta foi organizar o atendimento e promover a elaboração, a operacionalização e a avaliaçáo de propostas curriculares de acordo com as orientaçóes constantes no documento.

Desde essa perspectiva, no ano de 1994, constituiu-se uma equipe que desenvolveu o projeto de análise das propostas pedagógicas e curriculares de Educação Infantil. Por conseguinte, em 1995, acirrou-se o debate sobre a elaboração de propostas pedagógicas para o trabalho na Educação Infantil. Mediante o debate, a Coordenação de Educação MEC/COEDI realizou um diagnóstico sobre as propostas pedagógicas que, na época, estavam em funcionamento nas cidades brasileiras (AMORIM; DIAS, 2012).

Partindo de um panorama conceitual sobre as definiçóes e diferenciaçóes entre currículo e proposta pedagógica na Educação Infantil, teve início o trabalho desenvolvido por um grupo integrado pelas pesquisadoras Tisuko Morchida Kishimoto, Zilma de Moraes Ramos de Oliveira, Maria Lúcia Machado, Ana Maria Melo e Sônia Kraemer (CARVALHO, 2015).

Carvalho (2015) aponta a publicação, por meio do trabalho desenvolvido pelas pesquisadoras citadas, de dois importantes documentos que marcaram a efetivação de uma política curricular para a Educação Infantil no país: 1) Critérios para um Atendimento em Creches que Respeite os Direitos Fundamentais das Crianças (MEC,1995); 2) Propostas Pedagógicas e Currículo em Educação 
Infantil: um diagnóstico e a construção de uma metodologia de análise (MEC, 1996). No primeiro documento, foram apresentados critérios em relação aos modos de organização e funcionamento interno das creches. Ou seja, desde então,foram definidos diretrizes e programas de financiamento de creches, tanto governamentais como não governamentais. Por sua vez, o segundo documento focalizou a conceitualização e a definição das funçóes de um currículo para a educação de crianças em creches e pré-escolas e destacou a importância de serem elaboradas propostas curriculares específicas para a Educação Infantil (CARVALHO, 2015).

Nesse sentido, cabe salientar que a retomada e a reafirmação do direito à Educação Infantil se deram também em razão da homologação da Lei de Diretrizes e Bases da Educação Nacional (LDBEN- BRASIL, 1996), a partir da qual a Educação Infantil passou a ser considerada a primeira etapa da Educação Básica. Por essa razão, pode-se afirmar que a LDBEN (BRASIL,1996) demarcou o atendimento em creches, para as crianças de 0 a 3 anos, e na pré-escola, para as crianças de 4 a 6 anos. Além disso, a referida lei definiu que a primeira etapa da Educação Básica teria como objetivo central o desenvolvimento integral da criança até os 6 anos de idade, em seus aspectos físico, psicológico, intelectual e social, de modo complementar à ação da família e da comunidade (FILHO; NUNES, 2013).

Conforme Carvalho (2015), é válido ressaltar que, a partir da LDBEN (BRASIL, 1996), teve início no Brasil a transição das instituiçóes de Educação Infantil das Secretarias de Assistência Social para as Secretarias de Educação, para que fossem atendidas as normativas previstas na nova legislação. Em meio a esse contexto, foi publicado e divulgado, em 1998, o documento Subsídios para Credenciamento e Funcionamento de Instituiçóes de Educação Infantil (MEC, 1998). O referido documento tinha como objetivo orientar a elaboração, execução e avaliação de propostas pedagógicas de Educaçáo Infantil.

A formulação de todos esses aparatos normativos e instrutivos, de certa maneira, impulsionou a construçáo de uma nova identidade para a Educaçáo Infantil. Tal identidade articulou-se à superação do caráter assistencial ou preparatório para as etapas posteriores de escolarização, que por décadas fora preconizado. Ademais, vinculou-se a uma concepção de educação para a infância que buscasse estabelecer uma relação imanente entre cuidado e educação, entendendo que cuidar é também educar; por isso, são processos indissociáveis, envolvendo questóes como acolher, ouvir, encorajar e apoiar.

De acordo com Nunes e Corsino (2009), o processo de proposição de orientaçóes para a elaboração de propostas pedagógicas nas instituiçóes de Educação Infantil foi caracterizado por seu caráter democrático, pois houve discussáo com as redes de 
ensino e pesquisadores da área. Assim, é possível alegar que os documentos citados no decorrer desta seçáo promoveram o debate nacional em torno da elaboração da LDBEN (BRASIL, 1996), a qual efetivou a inclusão de creches e pré-escolas nos sistemas de ensino, tornando legais as principais diretrizes apontadas pela Política Nacional de Educação Infantil (AMORIM; DIAS, 2012).

\section{Entre debates, embates e proposições: políticas de currículo para a Educação Infantil}

Em 1998, de modo unilateral, não considerando as discussões realizadas até o momento, o entáo Ministério da Educação e do Desporto (MEC) instituiu um currículo nacional para o trabalho com as crianças por meio da publicação dos Referenciais Curriculares Nacionais de Educação Infantil (RCNEI) (CARVALHO, 2015). Os RCNEI foram divulgados como integrantes da coleção de Parâmetros Curriculares Nacionais (PCN) publicados para o Ensino Fundamental e Médio no país (AMORIM; DIAS, 2012).

Nesse sentido, é importante destacar que os RCNEI, mesmo antes de sua publicação, sofreram críticas da comunidade epistêmica da área de Educação Infantil, com pareceres negativos à sua publicação (AMORIM; DIAS, 2012). As críticas dos especialistas aos referenciais focaram-se no seu viés escolarizante e na concepção propedêutica de infância expressa no documento. Kramer (2006, p. 802) argumenta que os RCNEI “[...] não souberam como equacionar a tensão entre universalismo e regionalismos, além de terem desconsiderado a especificidade das diferentes infâncias." A partir das inúmeras e contundentes críticas, o MEC reelaborou algumas questóes dos referenciais com base nos pareceres dos professores consultados. Posteriormente, publicou os referenciais com a aprovação do Conselho Nacional de Educação (CNE), o qual os definiu como orientaçóes com caráter não obrigatório (CARVALHO, 2015).

Os referenciais foram publicados em três volumes, intitulados da seguinte maneira (MEC, 1998): 1) Introdução (apresenta a história das instituiçôes de Educação Infantil; uma breve discussão sobre as relaçóes existentes entre cuidar, educar e brincar; a definição das competências profissionais do professor de Educação Infantil; os objetivos da Educação Infantil; e orientaçóes pontuais sobre o planejamento de projetos pedagógicos); 2) Formação Pessoal e Social (focaliza as interaçôes das crianças com os coetâneos e com elas mesmas, tomando como eixo central de trabalho os conceitos de Identidade e Autonomia); 3) Conhecimento de Mundo (descreve proposiçóes a serem desenvolvidas com as crianças, baseadas nos seguintes eixos: movimento, artes visuais, música, linguagem oral e escrita, natureza e sociedade, e matemática). 
Os volumes dos referenciais foram organizados de modo segmentado por faixa etária ( 0 a 3 anos e 4 a 6 anos), desconsiderando a existência de uma continuidade educativa que precisava ser abordada. A esse respeito, autores como Bujes (2002), Amorim e Dias (2012) e Carvalho (2015) apontam que os RCNEI (MEC, 1998) não apresentaram um avanço político, pedagógico e conceitual para a Educação Infantil. Isso porque, conforme os referidos autores, o documento não focalizou a Pedagogia da Infância ${ }^{3}$ como princípio educativo, uma vez que privilegiou o aluno, e não a criança. Ou seja, parecia buscar desenvolver um trabalho pedagógico voltado para disciplina, concentração e produtividade das crianças desde a mais tenra idade. A título de exemplo, evidencia-se nos RCNEI a presença de um currículo prescritivo por idade (dividido entre creche e pré-escola), no qual são privilegiadas áreas de conhecimento.

Além disso, de acordo com Amorim e Dias (2012), a publicação dos RCNEI demonstrou uma descontinuidade na produção dos documentos legais até então publicados pelo governo. Tal atitude unilateral ratificou equivocadamente a compreensão dos professores de Educação Infantil de que os RCNEI seriam uma proposta curricular nacional de caráter mandatório (LEITE; NUNES, 2013).

No final de 1998, o CNE apresentou as Diretrizes Curriculares Nacionais para a Educação Infantil (DCNEI) e, no início do ano seguinte, aprovou a Resolução CEB n.o 1, de 7 de abril de 1999. Esse documento foi instituído com o objetivo de orientar, em caráter mandatório, a elaboração das propostas pedagógicas das instituiçôes de Educação Infantil (NUNES; CORSINO, 2009). Nessa direção, de acordo com Carvalho (2015), as diretrizes evidenciaram um avanço em termos de políticas curriculares, pois enfatizaram a autonomia das instituições, definiram o cuidar e o educar como objetivos centrais das propostas pedagógicas e atribuíram centralidade ao eixo das interaçóes e brincadeiras como base do currículo da Educação Infantil.

Em 2001, o MEC, por meio do Plano Nacional de Educação, publicou três documentos para orientar os estados e municípios no desenvolvimento de políticas públicas para a qualificação do atendimento das crianças na Educação Infantil (AMORIM; DIAS, 2012). Desse modo, foram publicados a Política Nacional de Educação Infantil (MEC, 2005), os Parâmetros Nacionais de Qualidade para a

3 Compreende-se a Pedagogia da Infância como um conjunto de fundamentos e indicaçôes de ação pedagógica que tem como referência as crianças e as múltiplas concepçôes de infância em diferentes espaços educacionais. Desse modo, a perspectiva assumida por tal Pedagogia tem significado as crianças como seres humanos dotados de ação social (portadores de história, capazes de múltiplas relaçôes e produtores de formas culturais próprias) e afirmado a infância como uma categoria geracional, social, histórica e geograficamente construída (atravessada por variáveis de gênero, classe, religiáo e etnia) (BARBOSA, 2010). 
Educação Infantil (BRASIL, 2006) e os Indicadores de Qualidade na Educação Infantil (MEC, 2009).

Conforme afirma Carvalho (2015), a Política Nacional de Educação Infantil apresentou orientações específicas para as instituições elaborarem suas propostas pedagógicas a partir das Diretrizes Curriculares Nacionais (BRASIL, 2010). Ou seja, a orientação legal enfatizou que as propostas pedagógicas deveriam explicitar concepçóes referentes à metodologia, ao processo de ensino/ aprendizagem e à avaliação.

Quanto aos Parâmetros Nacionais de Qualidade para a Educação Infantil (BRASIL, 2006), pode-se afirmar que estabeleceram padróes de referência a serem considerados em relação a três aspectos: 1) proposta pedagógica da Educação Infantil; 2) profissionais;3) infraestrutura das instituiçóes. Desde então, tais padrôes foram assumidos como orientadores para o sistema educacional no que concerne à organização e ao funcionamento das instituiçóes de Educação Infantil. $\mathrm{O}$ documento ressaltou ainda que as propostas pedagógicas das instituiçóes de Educação Infantil deveriam ser pautadas nos princípios de participação, contextualização, unidade e historicidade (AMORIM; DIAS, 2012).

É importante esclarecer que muitos dos objetivos previstos no Plano Nacional de Educação (BRASIL, 2001) para a Educação Infantil não foram atingidos. Em razão disso, foram incluídos novamente no Plano Nacional de Educação, cuja homologação ocorreu em 2014. Nesse sentido, a elaboração e a implementaçáo do novo Plano Nacional de Educação podem ser consideradas uma oportunidade para que a educaçáo da primeira infância seja colocada entre as prioridades educacionais no Brasil.

Em decorrência dos Parâmetros Nacionais de Qualidade (BRASIL, 2006), os Indicadores de Qualidade na Educação Infantil (MEC, 2009) apresentaram orientaçôes que permitiram a criação de instrumentos para o credenciamento de instituiçôes e a elaboração de diagnósticos (FLORES; ALBUQUERQUE, 2015). Para tanto, foi desenhado um instrumento de autoavaliação da qualidade das instituiçóes, em que deveriam ser consideradas sete dimensóes: planejamento institucional; multiplicidade de experiências e linguagens; interações; promoção da saúde; espaços, materiais e mobiliários; formação e condiçóes de trabalho de professores e demais profissionais; cooperação e troca com as famílias e participação na rede de proteção social (CARVALHO, 2015).

Além dos documentos elencados, foram publicadas, em 2009, as novas Diretrizes Curriculares Nacionais para a Educação Infantil (BRASIL, 2010), as quais passaram a ser observadas na elaboração das propostas pedagógicas das instituições de Educação Infantil, revogando-se as diretrizes aprovadas anteriormente (AMORIM; DIAS, 2012). As novas diretrizes retomaram os 
princípios éticos, políticos e estéticos que haviam sido definidos na resolução anterior, estabelecendo as interaçóes e as brincadeiras como eixos norteadores do currículo (FLORES; ALBUQUERQUE, 2015).

Pelos aspectos descritos, é possível afirmar que as DCNEI (BRASIL, 2010) avançaram teoricamente no âmbito da concepção de currículo para a Educação Infantil, definindo-o como "[...] um conjunto de práticas que buscam articular as experiências e os saberes das crianças com os conhecimentos que fazem parte do patrimônio cultural, artístico, científico e tecnológico." (BRASIL, 2010). Essa concepção de currículo, segundo Carvalho (2015), evidenciou respeito às peculiaridades das crianças ao dar centralidade à articulação das experiências e dos saberes das crianças com os conhecimentos historicamente produzidos.

Diante dessa lógica, Campos e Barbosa (2015) apontam que as diretrizes definiram princípios orientadores de um trabalho pedagógico comprometido com a qualidade e com oportunidades de desenvolvimento para todas as crianças. A orientação legal estabeleceu que todas as instituiçóes de Educação Infantil deveriam elaborar propostas curriculares nas quais fossem planejados e discutidos os usos do tempo, do espaço e dos materiais no cotidiano das práticas desenvolvidas com as crianças. Nesse sentido, o texto do documento explicitou os objetivos e as condiçóes para a organizaçáo curricular, considerou a Educação Infantil em territórios não urbanos, a importância da parceria com as famílias, as experiências que deveriam ser desenvolvidas nas rotinas e fez recomendaçóes em relaçáo aos processos de avaliação a serem observados no acompanhamento das crianças (BRASIL, 2010). Em tal concepção, pode-se alegar que os aspectos citados contribuem efetivamente para a elaboração de propostas que levem em consideração a criança dentro de suas potencialidades, como indivíduo que, além de sua história, tem seus direitos (CAMPOS; BARBOSA, 2015).

\section{Impasses: os assédios à Educação Infantil}

A agenda latino-americana para a Educação Infantil está atualmente alicerçada na intersecção de duas lógicas discursivas: uma referenciada nos direitos sociais das crianças, consubstanciados em legislaçóes nacionais específicas; outra, na lógica economicista, que atribui à Educação Infantil o papel de promover a formação do cidadão do futuro (SHORE; WRIGHT, 1997; MOSS, 2011; CAMPOS; CAMPOS, 2012; CARVALHO, 2016). Cabe destacar que a segunda lógica, devido à pressáo dos organismos internacionais, tem obtido algumas vitórias no que tange às políticas de Educação Infantil no país. Como exemplo, convém citar a ampliação do Ensino Fundamental e a obrigatoriedade da Educação Infantil aos 4 anos de idade. 
No segundo semestre de 2005, foi aprovado no Congresso Nacional um projeto de lei que, contando com o aceite da Presidência da República, redefiniu a faixa de ingresso das crianças aos 6 anos no Ensino Fundamental. Esse encaminhamento, sem discussão com os educadores organizados, sem nenhum tipo de consulta à população, à sociedade civil, ao CNE e ao MEC, demonstrou profundo desrespeito com os processos educacionais (CRAIDY; BARBOSA, 2012).

A Lei federal n. ${ }^{\circ} 11.114 / 2005$ foi aprovada sem que houvesse uma adequação do sistema de ensino. Dessa forma, escolas públicas e privadas foram induzidas a receber as crianças que estavam fora da escola sem ter conseguido preparar os professores, os pais e as crianças. A esse respeito, Craidy e Barbosa (2012, p. 32) afirmam que "[...] o problema maior não foi a definição de que as crianças de 6 anos deveriam iniciar o Ensino Fundamental, mas sim o que se passou a fazer com as crianças." Para as referidas autoras, a solução, certamente, não seria antecipar a entrada das crianças em um ensino falido, mas discutir e repensar esse ensino. As consequências da ampliação do Ensino Fundamental de oito para nove anos de duração, de acordo com Craidy (2014), têm ocasionado mudanças no currículo da pré-escola e, em muitos casos, uma intensificação precoce do processo de escolarização das crianças na Educação Infantil.

Em 2006, outra lei também acabou por atingir a Educação Infantil, a Lei n. ${ }^{\circ} 11.274$, de 6 de fevereiro, ampliando o Ensino Fundamental para nove anos e tornando obrigatória a inclusão da criança de 6 anos nesse nível de ensino (CRAIDY; BARBOSA, 2012). À época, surgiram impasses devido a incertezas em relação aos profissionais que estariam habilitados a atuar com as crianças de 6 anos (a partir de então inseridas no Ensino Fundamental). Houve ainda dúvidas quanto ao tipo de açóes pedagógicas que deveriam ser desenvolvidas e priorizadas com esse grupo de crianças. Em razáo dessa lei, decorreu a Emenda Constitucional n. ${ }^{\circ} 53$, de 19 de dezembro de 2006, a qual redefiniu a faixa etária compreendida no atendimento da Educação Infantil para 0 a 5 anos. Desse modo, com base na exposição, cabe referir que as Leis n. ${ }^{\circ} 11.114 / 2005$ e 11.274/2006 tiveram um caráter marcadamente inconstitucional.

Alguns anos depois, a Educação Infantil se tornou alvo de um novo impasse. A Emenda Constitucional n. ${ }^{\circ}$ 59/2009 tornou obrigatória a matrícula das crianças a partir dos 4 anos de idade na Educação Infantil. Por essa via, pode-se afirmar que a obrigatoriedade não produziu necessariamente a ampliação democrática e a qualidade da oferta, pois rompeu com a concepção educacional expressa na Constituição.Ratificando o argumento, Craidy (2014) declara que o fato de a escola se tornar obrigatória aos 4 anos traz para a pré-escola uma concepção que a identifica de forma inadequada com o Ensino Fundamental, tanto nos conteúdos 
quanto na metodologia. Dessa maneira, “[...] podemos encontrar pré-escolas em que as crianças de 4 e 5 anos ficam sentadas em fileiras durante quase todo o período realizando atividades em apostilas." (CRAIDY, 2014, p.179).

Além disso, a obrigatoriedade da pré-escola faz com que a creche destinada a crianças de 0 a 3 anos acabe sendo negligenciada, fato comprovado por a faixa etária dos 0 aos 3 anos ainda ser a que tem apresentado o menor índice de atendimento no país (CRAIDY, 2014). Por essa razão, a prioridade de oferta de Educaçâo Infantil para as crianças de 4 anos, devido a sua obrigatoriedade, vem ocasionando um crescente deslocamento do atendimento das crianças de 0 a 3 anos para a esfera privada filantrópica. Afinal, como promover a universalização do atendimento da Educação Infantil, e não apenas da pré-escola (CAMPOS; BARBOSA, 2015)?

Prosseguindo a discussão sobre os assédios à Educação Infantil, conforme Carvalho (2016), é importante destacar que, em 2010, a Secretaria de Assuntos Estratégicos (SAE), órgão diretamente vinculado à Presidência da República, aplicou uma avaliação em larga escala, a ASQ-3, tendo em vista a aferição do desenvolvimento das crianças e a qualidade dos serviços prestados por instituiçóes públicas de Educação Infantil na cidade do Rio de Janeiro.Por meio da parceria entre a SAE e a Secretaria Municipal de Educação do Rio de Janeiro, houve a aplicação do instrumento avaliativo ASQ-3 a crianças de 500 creches, com o objetivo de evidenciar sua potencialidade para a possível construção de uma política avaliativa das crianças em nível nacional.

Esse instrumento tomou como padrão normativo de excelência de desenvolvimento a classe média branca estadunidense (PENN, 2002; CARVALHO, 2016). Os resultados da avaliação realizada apontaram que $26 \%$ das crianças cariocas submetidas aos testes se encontravam em desvantagem em relação aos seus pares estadunidenses. No site da SAE, foi apresentado um ranking das creches que obtiveram os melhores resultados em termos de desenvolvimento das crianças. Sem dúvida alguma, tratouse de uma interpretaçáo economicista da educação, baseada em parâmetros americanos do que seja uma Educação Infantil de qualidade (CARVALHO, 2016). Esses parâmetros são criticados por Penn (2002), quando afirma que os Estados Unidos dispóem de um dos mais desiguais e injustos sistemas de Educação Infantil. A esse respeito, cabe ressaltar que a aplicação dos testes foi intensamente criticada em nível nacional pelos pesquisadores da área da Educação Infantil, o que fez o governo recuar da decisão de expandir as testagens e criar uma comissáo de especialistas para a elaboraçáo de uma Política de Avaliação da Educação Infantil cujo foco seja o contexto no qual é desenvolvido o trabalho com as crianças. 
Contemporaneamente, na esteira dos ataques à Educação Infantil, é preciso destacar também a criação, pelo governo federal, do Programa Criança Feliz, com o Decreto n. ${ }^{\circ}$ 8.869/2016. Coordenado pelo Ministério do Desenvolvimento Social e Agrário (MDSA), a iniciativa visa promover o desenvolvimento integral das crianças na primeira infância, tendo como foco gestantes e crianças de até 3 anos beneficiárias do Bolsa Família, e as de até 6 anos e suas famílias usuárias do Benefício de Prestaçáo Continuada (BPC). No âmbito do programa, conforme consta no decreto, as famílias serão acompanhadas por profissionais, os quais realizarão visitas domiciliares periódicas. Além disso, o decreto institui que o grupo gestor do programa será coordenado pelo MDSA e composto por representantes dos Ministérios da Justiça e Cidadania, Educação, Cultura e Saúde, os quais planejarão e articularão as ações a serem desenvolvidas. A participação dos estados, dos municípios e do Distrito Federal se dará por meio de adesão.

A leitura do decreto que originou o Programa Criança Feliz evidencia que as ações previstas se centram, sobretudo, na educação das famílias, não existindo nenhuma referência à Educação Infantil. Trata-se, em suma, de uma concepção de educação baseada em uma lógica econômica (PENN, 2002; MOSS, 2011; CARVALHO, 2016) que reedita políticas assistencialistas e compensatórias desenvolvidas em nosso país antes da Constituição Federal (BRASIL, 1988). O que chama a atenção é o fato de que esse projeto vem sendo apresentado no governo Michel Temer como a principal política para as crianças de 0 a 3 anos, o que resulta na redução da função da Educação Infantil no atendimento de qualidade em creches (com espaços, materiais e profissionais qualificados) às crianças de 0 a 3 anos em nosso país. Contrariando tal perspectiva de cunho assistencialista, a qual parecia ter sido superada, Teles (2015, p.31) afirma que não podemos esquecer que a "[...] creche é uma política pública de fortalecimento da sociedade e da cidadania”, devendo ser uma instituição laica, com profissionais qualificados para um trabalho educacional e social que atenda às demandas da população.

\section{Longe de concluir: desafios futuros para a Educação Infantil}

A apresentação das conquistas legais, bem como das lutas sendo travadas no campo da Educação Infantil desde seu reconhecimento como direito constitucional, possibilita dimensionar a complexidade e os inúmeros desafios que ainda se apresentam para a política de educação voltada para as crianças de 0 a 5 anos de 
idade. Nos últimos anos, foram registrados importantes avanços no âmbito das políticas de Educação Infantil - inclusão da Educação Infantil na esfera da Educação Básica, adoção de políticas públicas de financiamento, crescente investimento na formação dos profissionais atuantes na área, além de vários avanços conceituais expressos nos vários documentos de orientação, dentre os quais se destacam as Diretrizes Curriculares Nacionais para a Educação Infantil (BRASIL, 2010).

Por outro lado, de acordo com Leite e Nunes (2013, p. 88), “[...] o desafio para a próxima década é estreitar a distância entre o que é proposto para um trabalho que respeite os direitos das crianças e o que tem sido traduzido em orientaçóes e práticas municipais", pois, se há um consenso entre pesquisadores sobre o caráter educativo da Educação Infantil, o mesmo não acontece em relação à definição do que isso significa nas açóes concretas.

Ratificando o argumento, é importante citar, por exemplo, que as metas do Plano Nacional de Educação (PNE) 2001-2011 (BRASIL, 2001) de atendimento de $50 \%$ das crianças de 0 a 3 anos em creches e de $80 \%$ das crianças de 4 a 6 anos na pré-escola não foram alcançadas. De acordo com Craidy (2014, p.184), "[...] na média nacional, apenas $18 \%$ das crianças frequentavam creches em 2011.” Já para as de 4 a 6 anos incompletos, $o$ atendimento não ficou muito longe da meta de $80 \%$, já que $72 \%$ frequentavam a escola.

Nesse sentido, é urgente que, para além da universalização da pré-escola, devido a sua obrigatoriedade, o atendimento das crianças de 0 a 3 anos em $50 \%$ até 2024 deixe de ser apenas uma meta do atual Plano Nacional de Educação (PNE 2014-2024) (BRASIL, 2014) e efetivamente se torne uma prática, assegurando também o direito dos bebês e crianças bem pequenas a uma Educação Infantil pública e de qualidade. Por esse motivo, é preciso garantir, impreterivelmente, a unidade pedagógica da Educação Infantil, redobrando ações para recuperar a segmentação histórica que continua excluindo boa parte dos bebês e crianças bem pequenas da educação (CAMPOS; CAMPOS, 2012). Isso porque, atualmente, sabemos que existe um enorme déficit de creches em nosso país, sendo que menos de $20 \%$ das crianças de 0 a 3 anos têm conseguido vagas em instituições públicas (CRAIDY, 2014). Por essa razão, conforme aponta Teles (2015, p. 32), existe a necessidade de que se reivindique o atendimento das crianças de 0 a 3 anos, "[...] sob pena de se perder a conquista histórica dos anos de 1980, que foi a criação de creches públicas, laicas e com a participação permanente da sociedade.”

Mais do que o desafio de atendimento apresentado, Craidy e Barbosa (2012, p. 35) lembram que é necessário "[...] garantir que as crianças vivam a experiência da infância” na Educação Infantil. Logo, cabe destacar que hoje está sendo vivenciado um importante momento na afirmação da Pedagogia da Infância com base na discussão do currículo da Educação Infantil na Base Nacional 
Comum Curricular (BNCC) $)^{4}$. A BNCC (MEC, 2017), fundamentada nos princípios éticos, políticos e estéticos apresentados nas Diretrizes Curriculares Nacionais para a Educação Infantil (BRASIL, 2010), contempla direitos de aprendizagem (conviver, brincar, participar, explorar, expressar e conhecer-se) e de desenvolvimento para a etapa. Sem dúvida, as orientaçóes previstas na Base Nacional Comum Curricular evidenciam indefectivelmente a reiteração da concepçáo de currículo prevista nas DCNEI (BRASIL, 2010), definindo, de modo mais propositivo, a organizaçáo de propostas que tomem o cotidiano das crianças como mote do planejamento (CAMPOS; BARBOSA, 2015).

Sob tal perspectiva, o documento da BNCC (MEC, 2017) afirma que os direitos de aprendizagem devem ser garantidos a partir de um trabalho com os seguintes campos de experiências: 1) o eu, o outro e o nós; 2) corpo, gestos e movimentos; 3) traços, sons, cores e formas; 4) escuta, fala, pensamento e imaginação; 5) espaços, tempos, quantidades, relaçóes e transformações. Esses campos de experiências devem colocar no centro do projeto educativo os eixos das interaçóes e das brincadeiras, definidos como estruturantes do currículo nas DCNEI (BRASIL, 2010). Os campos não são tratados como divisóes de áreas ou componentes curriculares, mas colocam "[...] no centro do projeto educativo o fazer e o agir das crianças, tendo em vista as contínuas e participativas interaçóes de meninos e meninas." (FOCHI, 2015, p. 221). Ou seja, o modo como as crianças vivem, as situaçóes que enfrentam e as trocas que estabelecem com tudo aquilo que as rodeia no cotidiano pode ser constituidor de experiências. Para tanto, é preciso que seja organizado e sistematizado um currículo que otimize as descobertas e as construçóes infantis, respeitando as crianças em suas especificidades.

Sendo assim, é possível alegar que as conquistas, impasses e desafios enfrentados pelas Políticas de Educação Infantil, descritos no decorrer do artigo, evidenciam que a primeira etapa da Educação Básica "[...] se constituiu e continua sendo constituída em um campo de disputas, o qual atualmente ainda é configurado pela luta da efetivação de um direito definido há mais de 27 anos." (CAMPOS; BARBOSA, 2015, p. 356). Portanto, para finalizar este artigo, mesmo sabendo que as discussões sobre as Políticas de Educação Infantil ainda estão longe de serem concluídas e que muitos desafios terão que ser enfrentados nos próximos anos, faz sentido, assim como Marco Polo (CALVINO, 1990, p. 79), reconhecer que é preciso que continuemos descrevendo as pedras, pois "[...] sem pedras o arco não existe." Desse modo, quem sabe consigamos

4 Está sendo tomada como referência a terceira versão da Base Nacional Comum Curricular (MEC, 2017). 
construir uma Pedagogia da Infância que se torne realidade tanto no contexto das políticas educacionais em termos de universalização do atendimento das crianças (sem segmentação de faixas etárias) como na qualificação das práticas cotidianas das escolas de Educação Infantil.

\section{Referências}

AMORIM, Ana Luisa; DIAS, Adelaide Alves. Currículo e Educação Infantil: uma análise dos documentos curriculares nacionais. Espaço do Currículo, v .4, n. 2, p. 125-137, set. 2011/mar. 2012.

BARBOSA, Maria Carmem Silveira. Pedagogia da infância. In: OLIVEIRA, D. A.; DUARTE, A. M. C.; VIEIRA, L. M. F. Dicionário: trabalho, profissão e condição docente. Belo Horizonte: UFMG/Faculdade de Educação, 2010. p. 10-12.

BRASIL. Constituição da República Federativa do Brasil .Diário Oficial da Uniáo, Brasília, DF, 5 out. 1988.

BRASIL. Decreto n. ${ }^{\circ}$ 8.869, de 5 de outubro de 2016. Institui o Programa Criança Feliz. Diário Oficial da Uniáo, Brasília, DF, 5 out. 2016. Seção 1, p. 1.

BRASIL. Lei n. ${ }^{\circ}$ 8.069, de 13 de julho de 1990. Dispóe sobre o Estatuto da Criança e do Adolescente e dá outras providências. Diário Oficial da Uniáo, Brasília, DF, 16 jul. 1990.

BRASIL. Lei n. ${ }^{\circ}$ 9.394, de 20 de dezembro de 1996. Estabelece as diretrizes e bases da educação nacional. Diário Oficial da Uniáo, Brasília, DF, 23 dez. 1996.

BRASIL. Lei n. ${ }^{\circ}$ 10.172, de 9 de janeiro de 2001. Aprova o Plano Nacional de Educação e dá outras providências. Diário Oficial da Uniáo, Brasília, DF, 10 jan. 2001.

BRASIL. Lei n. ${ }^{\circ} 11.114$, de 16 de maio de 2005 . Altera os arts. $6^{\circ}, 32$ e 87 da Lei no 9394/96, de 20 de dezembro de 1996, com o objetivo de tornar obrigatório o início do ensino fundamental aos seis anos de idade. Diário Oficial da Uniáo, Brasília, DF, 17 maio 2005.

BRASIL. Lei n. ${ }^{\circ} 11.274$, de 6 de fevereiro de 2006. Altera a redação dos arts. 29, 30, 32 e 87 da Lei n. 9.394, de 20 de dezembro de 1996, que estabelece as diretrizes e bases para a educação nacional, dispondo sobre a duração de 9 (nove) anos para o ensino fundamental, com matrícula obrigatória a partir dos 6 (seis) anos de idade. Diário Oficial da Uniáo, Brasília, DF, 7 fev. 2006. 
BRASIL. Lei n. ${ }^{\circ}$ 12.796, de 4 de abril de 2013. Altera a Lei n. ${ }^{\circ} 9.394$, de 20 de dezembro de 1996, que estabelece as diretrizes e bases da educação nacional, para dispor sobre a formação dos profissionais da educação e dar outras providências. Diário Oficial da Uniáo, Brasília, DF, 5 abr. 2013.

BRASIL. Lei n. ${ }^{\circ}$ 13.005, de 25 de junho de 2014. Aprova o Plano Nacional de Educação e dá outras providências. Diário Oficial da Uniáo, Brasília, DF, 26 jun. 2014.

BRASIL. Constituição (1988). Emenda Constitucional n. ${ }^{\circ}$ 53, de 19 de dezembro de 2006. Dá nova redação aos arts. 7º, 23, 30, 206, 208, 211 e 212 da Constituição Federal e ao art. 60 do Ato de Disposiçóes Constitucionais. Diário Oficial da União, Brasília, DF, 20 dez. 2006. Seção 1, p.5-6.

BRASIL. Constituição (1988). Emenda constitucional n. ${ }^{\circ}$ 59, de 11 de novembro de 2009. Fixa a obrigatoriedade do ensino de quatro a dezessete anos. Diário Oficial da Uniáo, Brasília, DF, 12 nov. 2009.

BRASIL. Ministério da Educação. Secretaria de Educação Básica. Diretrizes curriculares nacionais para a educaçáo infantil. Brasília, DF: MEC/SEB, 2010.

BRASIL. Ministério da Educação. Secretaria de Educação Básica. Parâmetros Nacionais de Qualidade para a Educação Infantil. Brasília, DF: MEC/SEB, 2006.

BUJES, Maria Isabel Edelweiss. Infância e maquinarias. Rio de Janeiro: DP\&A, 2002.

CALVINO, Italo. As cidades invisíveis. São Paulo: Companhia das Letras, 1990.

CAMPOS, Maria Malta. Infância como construção social: contribuiçóes do campo da Pedagogia. In: VAZ, Alexandre Fernandez et al. (Org.). Educaçáo Infantil e sociedade: questôes contemporâneas. Nova Petrópolis: Nova Harmonia, 2012. p.11-20.

CAMPOS, Rosânia; BARBOSA, Maria Carmem Silveira. BNCC e Educação Infantil: quais as possibilidades? Revista Retratos da Escola, v. 9, n. 17, p. 353366, jul./dez. 2015.

CAMPOS, Roselane Fátima; CAMPOS, Rosânia. Políticas para a Educação Infantil e os desafios do novo Plano Nacional de Educação: similitudes e divergências entre as experiências brasileiras e de outros países latino-americanos. In: FARIA, Ana Lúcia Goulart; AQUINO, Ligia Maria Leão (Org.). Educaçáo Infantil e PNE: questóes e tensôes para o século XXI. Campinas: Autores Associados, 2012. p. 9-30. 
CARVALHO, Rodrigo Saballa de. Análise do discurso das diretrizes curriculares nacionais de educação infantil: currículo como campo de disputas. Educaçáo, v. 38, n. 3, p. 466-476, set./dez. 2015.

CARVALHO, Rodrigo Saballa de. O investimento na formaçáo do cidadão do futuro: a aliança entre economia e educação infantil como estratégia da governamentalidade contemporânea. Educação em Revista, v. 32, n. 2, p. 229253, abr./jun. 2016.

CONSELHO NACIONAL DE EDUCAÇÃO. Resolução CEB n. ${ }^{\circ}$ 01, de 07 de abril de 1999. Institui as Diretrizes Curriculares Nacionais para a Educação Infantil. Diário Oficial da Uniáo, Brasília, DF, 13 abr. 1999. Seção 1, p. 18.

CRAIDY, Carmem Maria. Educação Infantil: espaço emergente nas Políticas de Escolarização Contemporâneas. In: SILVA, Roberto Dias et al. (Org.). Políticas contemporâneas de escolarizaçáo no Brasil: uma agenda investigativa. Curitiba: CRV, 2014. p.177-186.

CRAIDY, Carmem Maria; BARBOSA, Maria Carmem Silveira. Ingresso obrigatório no Ensino Fundamental aos seis anos: falsa solução para um falso problema. In: BARBOSA, Maria Carmem Silveira et al. (Org.). A infância no ensino fundamental de 9 anos. Porto Alegre: PENSO, 2012. p. 19-36.

FLORES, Maria Luiza Rodrigues; ALBUQUERQUE, Simone Santos. Diretrizes Curriculares Nacionais para a Educação Infantil: algumas interfaces entre as políticas e as práticas. In: FLORES, Maria Luiza Rodrigues; ALBUQUERQUE, Simone Santos (Org.). Implementaçáo do Proinfância no Rio Grande do Sul: perspectivas políticas e pedagógicas. Porto Alegre: EDIPUCRS, 2015. p. 17-38.

FOCHI, Paulo Sérgio. Ludicidade, continuidade e significatividade nos campos de experiência. In: FINCO, Daniela et al. (Org.). Campos de experiências na escola da infância: contribuições italianas para inventar um currículo de Educação Infantil brasileiro. Campinas: Edições Leitura Crítica, 2015. p. 221232.

KRAMER. Sônia. As crianças de 0 a 6 anos nas Políticas Educacionais no Brasil: educação infantil e/é fundamental. Educaçáo e Sociedade, Campinas, v. 27, n. 96, p. 797-818, out. 2006.

LEITE FILHO, Aristeo Gonçalves; NUNES, Maria Fernanda. Direitos da criança à Educação Infantil: reflexóes sobre a história e a política. In: KRAMER, Sonia; NUNES, Maria Fernanda et al. (Org.). Educaçáo Infantil: formação e responsabilidade. Campinas: Papirus, 2013. p. 67-88. 
LEITE FILHO, Aristeo Gonçalves; NUNES, Maria Fernanda. Direitos da criança à Educação Infantil: reflexôes sobre a história e a política. In: KRAMER, Sonia; NUNES, Maria Fernanda; CARVALHO, Maria Cristina (Org.). Educaçáo Infantil: formação e responsabilidade. Campinas: Papirus, 2013. p. 67-88.

MINISTÉRIO DA EDUCAÇÃO (MEC). Base nacional comum curricular. Brasília, DF: MEC, 2017.

MINISTÉRIO DA EDUCAÇÃO (MEC). Secretaria de Educação Básica. Indicadores da Qualidade na Educação Infantil. Brasília, DF: MEC/SEB, 2009. MINISTÉRIO DA EDUCAÇÃO (MEC). Secretaria de Educação Básica. Política Nacional de Educaçáo Infantil: pelo direito das crianças de zero a seis anos à educação. Brasília, DF: MEC/SEB/DPE/COEDI, 2005.

MINISTÉRIO DA EDUCAÇÃO E DO DESPORTO (MEC). Secretaria de Educação Fundamental. Critérios para um atendimento em creches que respeite os direitos fundamentais das crianças. Brasília, DF: MEC/SEF/DPE/ COEDI, 1995.

MINISTÉRIO DA EDUCAÇÃO E DO DESPORTO (MEC). Secretaria de Educação Fundamental. Referencial curricular nacional para a educaçáo infantil. Brasília, DF: MEC/SEF, 1998.

MINISTÉRIO DA EDUCAÇÃO E DO DESPORTO (MEC). Secretaria de Educação Fundamental. Coordenação de Educação Infantil. Política Nacional de Educaçáo Infantil. Brasília, DF: MEC/SEF/COEDI, 1994.

MINISTÉRIO DA EDUCAÇÃO E DO DESPORTO (MEC). Secretaria de Educação Fundamental. Departamento da Política de Educação Fundamental. Coordenação-Geral de Educação Infantil. Propostas pedagógicas e currículo em Educaçáo Infantil: um diagnóstico e a construção de uma metodologia de análise. Brasília, DF: MEC/SEF/DPEF/COEDI, 1996.

MINISTÉRIO DAEDUCAÇÃO EDO DESPORTO(MEC). Secretaria deEducação Fundamental. Departamento de Política da Educação Fundamental. CoordenaçãoGeral de Educação Infantil. Subsídios para credenciamento e funcionamento de instituiçóes de Educaçáo Infantil. Brasília, DF: MEC/SEF/DPEF/CGEI, 1998.

MOSS, Peter. Qual o futuro da relação entre Educação Infantil e ensino obrigatório? Cadernos de Pesquisa, Sáo Paulo, v. 41, p. 142-159, jan./abr. 2011.

NUNES, Maria Fernanda Rezende; CORSINO, Patrícia. A institucionalização da infância: antigas questôes e novos desafios. In: CORSINO, Patrícia (Org.). 
Educação Infantil: cotidiano e políticas. Campinas: Autores Associados, 2009. p. 15-32.

PENN, Helen. Primeira infância: a visão do Banco Mundial. Cadernos de Pesquisa, São Paulo, v. 115, n. 2, p. 7-24, 2002.

SHORE, Cris; WRIGHT, Susan. Antropology of Policy: critical perspectives on governance and power. London: Routledge, 1997.

TELES, Maria Amélia Almeida. A participação feminina na luta por creches! In: FINCO, Daniela; GOBBI, Márcia Aparecida et al. (Org.). Creche e feminismos: desafios atuais para uma educação descolonizadora. Campinas: Ediçóes Leituras Críticas, 2015. p. 21-34. 